\title{
Adrenal Gland Angiosarcoma
}

National Cancer Institute

\section{Source}

National Cancer Institute. Adrenal Gland Angiosarcoma. NCI Thesaurus. Code C48320.

A rare malignant soft tissue neoplasm arising from the vascular endothelium of the adrenal gland. 